\title{
Collaboration Analytics Need More Comprehensive Models and Methods. An Opinion Paper
}

\author{
Areum Han ${ }^{1}$, Florian Krieger $^{2}$, Samuel Greiff ${ }^{3}$
}

\begin{abstract}
As technology advances, learning analytics is expanding to include students' collaboration settings. Despite their increasing application in practice, some types of analytics might not fully capture the comprehensive educational contexts in which students' collaboration takes place (e.g., when data is collected and processed without predefined models, which forces users to make conclusions without sufficient contextual information). Furthermore, existing definitions and perspectives on collaboration analytics are incongruent. In light of these circumstances, this opinion paper takes a collaborative classroom setting as context and explores relevant comprehensive models for collaboration analytics. Specifically, this paper is based on Pei-Ling Tan and Koh's ecological lens (2017, Situating learning analytics pedagogically: Towards an ecological lens. Learning: Research and Practice, 3(1), 1-11. https://doi.org/10.1080/23735082.2017.1305661), which illustrates the co-emergence of three interactions among students, teachers, and content interwoven with time. Moreover, this paper suggests several factors to consider in each interaction when executing collaboration analytics. Agendas and recommendations for future research are also presented.
\end{abstract}

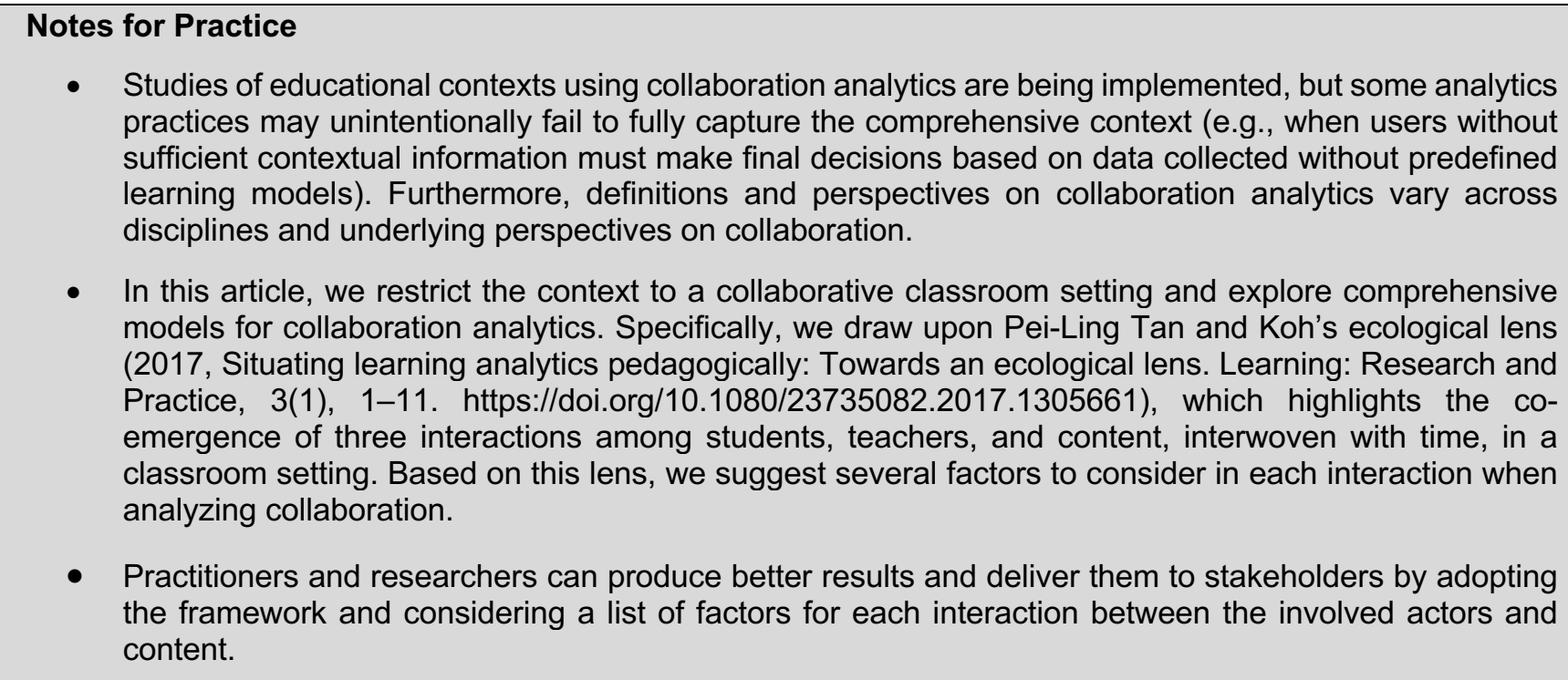

\section{Keywords}

Collaboration analytics, analytics framework, comprehensive perspective

Submitted: 22/06/20 - Accepted: 22/01/21 - Published: 09/04/21

Corresponding author ${ }^{1}$ Email: areum.han@uni.lu Address: University of Luxembourg, Faculty of Humanities, Education and Social Sciences, Campus Belval, Maison des Sciences Humaines, 11, Porte des Sciences, L-4366, Esch-sur-Alzette, Luxembourg. ORCID ID: https://orcid.org/0000-0001-6974-521X

${ }^{2}$ Email: florian.krieger@uni.lu Address: University of Luxembourg, Faculty of Humanities, Education and Social Sciences, Campus Belval, Maison des Sciences Humaines, 11, Porte des Sciences, L-4366, Esch-sur-Alzette, Luxembourg. ORCID ID: https://orcid.org/0000-0001-99818432

${ }^{3}$ Email: samuel.greiff@uni.lu Address: University of Luxembourg, Faculty of Humanities, Education and Social Sciences, Campus Belval, Maison des Sciences Humaines, 11, Porte des Sciences, L-4366, Esch-sur-Alzette, Luxembourg. ORCID ID: https://orcid.org/0000-0003-2900$\underline{3734}$

\section{Introduction}

As technology develops, more educational data is being collected and analyzed with respect to students' learning. Much of this data collection and analysis can be subsumed under the term learning analytics, defined as "measurement, collection, 
analysis and reporting of data about learners and their contexts, for purposes of understanding and optimizing learning and the environments in which it occurs" (Siemens \& Gašević, 2012, p. 1; Society for Learning Analytics Research, n.d.).

Concerns about learning analytics have grown alongside the rise of such large-scale data collection and analysis (Selwyn, 2019). One concern is the failure to understand educational contexts in a nuanced and sound way (Knox, 2017; Scheffel, Tsai, Gašević, \& Drachsler, 2019; Selwyn, 2019). The field of collaboration analytics does not seem to have escaped this concern. Importantly, collaboration analytics unites various technical approaches to capturing and analyzing data about collaboration (Martinez-Maldonado, Kay, Buckingham Shum, \& Yacef, 2019). That is, it focuses on collaborative aspects of learning under the umbrella term of learning analytics. Some argue that the analytic results of such interactions falsely assess collaboration quality (Stahl, 2011) because they do not consider the entire collaboration process, including elements such as user activities or the collaborative context (Chounta \& Avouris, 2016).

As Wise (2014) points out, such cases do indeed exist, although not every form of collaboration analytics neglects the collaboration context. For example, whereas some forms of collaborative analytics postulate specific models with systematic rules in alignment with the environment and later use these rules for data processing, the collected data can also be processed without such predefined learning models. On such occasions, users need to make their conclusions. If their understanding of the pedagogical context is insufficient, "locally contextualized questions" might not be solved, such as how the data is related to learning goals (p. 204). Let us take a hypothetical example of taciturn students in a discussion forum. Their inactivity might be due to their personal characteristics, but it can be problematic if the forum applies an instructional design like "[the] wheel and spoke social network" approach ${ }^{1}$ at the early stage of building novice groups (p. 205). If in such a case collaboration analytics does not provide comprehensive contextual information (e.g., instructional approach) and inferences are made based only on users themselves, inaccurate solutions or interpretations can be unintentionally derived from this insufficient contextual information.

Accordingly, it is crucial to comprehensively consider the educational context in collaboration analytics, especially because analytics results can be used as a form of assessment, providing students and teachers with insight into, for example, how learning can be identified or unfolds (Joksimović, Kovanović, \& Dawson, 2019; Knight, Buckingham Shum, \& Littleton, 2013). That is, understanding of the context affects how and what to measure within collaboration analytics, which in turn affects students' learning (Brown, Bull, \& Pendlebury, 1997). There are also more specific reasons why educational contexts should be considered comprehensively in the field of collaboration analytics. First of all, questions such as what constitutes collaboration or relevant skills are answered differently in different sociocultural contexts. This is because "knowledge is situated in unique sociocultural scenarios, negotiated within communities, constructed through purposeful social activities, and created through emergent interactions" (Brown, Collins, \& Duguid, 1989; Chen, Chang, Ouyang, \& Zhou, 2018, p. 22). Furthermore, students learn new skills and ideas in situated learning contexts "through interaction and collaboration" (Buckingham Shum \& Ferguson, 2012; Chen et al., 2018, p. 22; Tsoni \& Verykios, 2019; Vygotsky, 1978), for example, with "more knowledgeable other[s]" (i.e., teachers or peers) who can offer them guidance or encouragement (Tsoni \& Verykios, 2019, p. 2).

Despite the importance of considering educational contexts comprehensively, research in the field of collaboration analytics for students has mostly focused on students themselves (Joksimović et al., 2019). For example, researchers have studied essential factors for successful collaborative processes among students as well as potentially automatable aspects, while placing less emphasis on other components, such as teachers' pedagogical techniques, learning content, or the interactions between teachers and content in collaborative settings (Chounta \& Avouris, 2016; Dillenbourg, Järvelä, \& Fischer, 2009; Haataja et al., 2019; Reilly \& Schneider, 2019; Webb, 2008). While many researchers study these factors in the field of education, research on them in the field of collaboration analytics is still nascent (Prieto, Sharma, Dillenbourg, \& Jesús, 2016). Other aspects, such as collaboration trajectories over time, can also be considered in light of a comprehensive framework (e.g., coordination during collaborative problem-solving; Wiltshire, Steffensen, \& Fiore, 2019). Nevertheless, there is no commonly established framework that incorporates these comprehensive contexts into collaborative educational settings.

Moreover, collaboration analytics frameworks differ depending on what perspective on collaboration is taken. To fill in these gaps, underlying theoretical models of collaboration analytics should be advanced and extended to incorporate comprehensive educational contexts. Such a fine-grained understanding of contexts can reduce measurement error and enable better results to be produced and delivered to stakeholders, which should ultimately influence learning effectiveness. In light of the growing importance of learning analytics for both researchers and policymakers, it is essential to consider all important aspects. Therefore, this opinion article argues that a comprehensive understanding of educational contexts is required for collaboration analytics and proposes how such a comprehensive approach might be implemented.

To achieve this, perspectives and models from fields related to collaboration analytics are reviewed, with a focus on neglected areas. To shed light on these areas, we apply Pei-Ling Tan and Koh's (2017) lens from the field of education, which

\footnotetext{
${ }^{1}$ The wheel and spoke model is a type of spiral model for faster and multiple iterations of small teams (Ruparelia, 2010). 
spotlights the relationships among students, teachers, content, and time in collaborative settings, while also considering other models. Finally, agendas and possible challenges for future research are discussed. Since educational contexts can be interpreted in various ways, this article limits its consideration to classrooms, regardless of whether they are virtual or not (Cukurova, Luckin, \& Baines, 2018). Even within a given classroom, "multiple purposes, agents, resources and activities" (Roschelle, Dimitriadis, \& Hoppe, 2013, p. 524) exist from which sufficient insight can be drawn.

\section{What Is Collaboration Analytics?}

Collaboration analytics is defined differently by different researchers and disciplines. These disparities are rooted in diverse perspectives and theoretical models concerning the meaning of collaboration. By assuming that collaboration analytics can be described as the extension of learning analytics to collaborative settings, this article begins its exploration of what collaboration analytics is by first defining collaboration.

According to Dascalu, Trausan-Matu, McNamara, and Dessus (2015, p. 396), "collaboration can be perceived as a measure of interaction among participants centered on sharing ideas, fostering creativity for working in groups, and influencing others' points of view during the discussion." In contrast, Malmberg and colleagues (2019, p. 236) suggest that collaboration means "a construction of shared understanding through interaction with others, in which the participants are committed to or engaged in shared goals and problem solving." One difference between these two definitions concerns problem-solving. Malmberg and colleagues (2019) posit that problem-solving is part of collaboration, while Dascalu and colleagues (2015) merely highlight participants' interaction. Taking a more critical perspective, Graesser and colleagues (2018) identify diverse forms of collaboration, including collaborative work, learning, judgments, decision-making, and problem-solving ${ }^{2}$. That is, collaboration can exist in different forms for different purposes. Although none of these definitions covers every aspect of collaboration, they generally share a focus on social interaction in the collaboration process.

Among the various definitions and perspectives on collaboration, from the viewpoint of collaborative learning, MartinezMaldonado, Clayphan, and Kay (2013, p. 2) interpret collaboration analytics as "analysis techniques that can be applied to exploit rich interaction data captured" including "artificial intelligence approaches, data mining algorithms, process mining, statistics and visualizations." More recently, Martinez-Maldonado and colleagues (2019, p. 5) defined the term as any technical approach to capturing "data emanating from collaboration networks with complex relationships between their entities (people, tasks, tools)," "particularly in collocated contexts." Naturally, the collected data is "heterogeneous and unstructured," such as "text, images, video, application logs, [and] location data" (Martinez-Maldonado et al., 2019, p. 5). Nowadays, data from collaboration analytics is extended to include latent variables, such as learning regulation in the collaboration process (e.g., Malmberg et al., 2019; Ron, Berka, \& Sprang, 2009).

To recapitulate, efforts to define collaboration analytics are still ongoing, as is research on collaboration. Each definition of collaboration has a different focus, leading to inconsistencies and differences among the definitions and underlying perspectives on collaborative analytics. However, one commonality is that data from collaboration entities (i.e., people, tasks, tools; see Martinez-Maldonado et al., 2019) is analyzed and reported using a variety of techniques. Consequently, comprehensive yet non-reducible models are necessary to encompass all relevant aspects - without missing any collaboration entities. This is what is meant by comprehensive in this article. In the next section, we introduce comprehensive frameworks, which we argue should be given greater weight in collaboration analytics and its interpretations.

\section{Comprehensive Frameworks for Exploring Educational Contexts (i.e., a Collaborative Classroom Setting)}

It is evident that context is a frequently used term among education researchers (Cukurova et al., 2018); nonetheless, the term context is still polysemous and not easy to apply to teaching and learning. So far, context has been portrayed in two ways: (1) as a surrounding "container" or (2) as a changing part of life interwoven with human actions and artefacts (Cukurova et al., 2018, p. 323). This paper uses the term educational context in line with the second conceptualization, namely, as changing life interwoven with actions and artefacts among stakeholders in education (e.g., students, teachers, or parents).

\footnotetext{
${ }^{2}$ According to Graesser and colleagues (2018), the results of research on collaborative learning or decision-making cannot be extended or generalized to the collaborative problem-solving process because they differ in terms of "[t]he impact of a single team member on a group" (p. 62). An incompetent individual can be excluded from a learning or decision-making process because of their insufficient performance, which allows the group to continue to function; however, in collaborative problem-solving situations, a critical deadlock can arise due to an incompetent member, which the whole team must then overcome. While this argument seems reasonable, many studies do not distinguish collaborative problem-solving from collaborative learning or decision-making. For example, Kaendler, Wiedmann, Rummel, and Spada (2015, p. 506) state that "collaborative learning is the process of two or more students working together to find a joint solution to the group task at hand." Thus, this paper does not differentiate between different categories of collaboration.
}

ISSN 1929-7750 (online). The Journal of Learning Analytics works under a Creative Commons License, Attribution - NonCommercial-NoDerivs 3.0 Unported (CC BY-NC-ND 3.0) 
Given the expandability and variability of educational contexts, this article limits its consideration to classrooms (both physical and virtual; Cukurova et al., 2018). Learners can gather in either synchronous or asynchronous environments and form a large network or an affinity group (Buckingham Shum \& Ferguson, 2012). To understand these collaborative learning contexts, we can refer to multiple frameworks and theories from related literature. Several frameworks for comprehensively understanding learning or collaboration contexts, such as activity theory (e.g., Leontyev, 1978), have been constructed that seem suitable for understanding collaboration analytics in a collaborative classroom in a comprehensive manner. In this paper, a comprehensive manner means considering the full picture of a context, including all non-reducible elements, while not factoring in complexities that can differ across different underlying perspectives on collaboration, such as whether to include problem-solving.

One such example is the activity-based computing framework from the field of human-computer interaction, which decomposes group activities into three dimensions: (1) tasks and materials, (2) time and space, and (3) users (Bardram, 2005; Echeverria, Martinez-Maldonado, \& Buckingham Shum, 2019). Another approach is the activity-centred analysis and design framework. This framework outlines group activities along three dimensions: (1) set (i.e., the place of group activity and relevant objects), (2) epistemic (i.e., "both implicit and explicit knowledge oriented elements that shape the participants' tasks and working methods"), and (3) social (i.e., group composition, assigned roles, and responsibilities) (Echeverria et al., 2019, p. 4; Martinez-Maldonado, Goodyear, Kay, Thompson, \& Carvalho, 2016). More recently, Echeverria and colleagues (2019) added a further dimension to this framework: (4) the affective aspect.

Interestingly, the line of argumentation by Zimmermann, Lorenz, and Oppermann (2007) also encompasses these different dimensions. Acknowledged as one of the most comprehensive definitions of context (Verbert et al., 2012), this framework describes a context as "any information that can be used to characterize the situation of an entity"; here, an entity means "a person, place, or object that is considered relevant to the interaction between the user and the application, including the user and applications themselves" (Dey, 2001, p. 5; Zimmermann et al., 2007, p. 559). Their definition of changeable context and contextual information encompasses five categories:

- Individuality: entity-related information (e.g., learners' language);

- Time: points, ranges, and histories;

- Location: people's or resources-related locations, or virtual locations (IP addresses);

- Activity: information about goals, tasks, and actions;

- Relations: the relations among entities.

Zimmermann and colleagues' (2007) proposed definition stands in stark contrast to early works from the context-aware computing field, in which the context was considered as a surrounding container, which foregrounded scalar aspects alongside possible objects and services (Buckingham Shum \& Ferguson, 2012). Despite stemming from a different discipline, Zimmermann and colleagues' (2007) argument can be extended to or overlap with other frameworks for collaborative learning in classrooms.

One example of a framework reflecting these features is Pei-Ling Tan and Koh's (2017) ecological lens from the field of education. This framework is based on Bronfenbrenner's (1979) well-known ecological systems theory, which posits (1) that humans develop in a complex world with multi-layered and interrelated systems such as family and school and (2) that "our knowledge of development" depends on its "context, culture, and history" (Darling, 2007, p. 204). In line with Bronfenbrenner's theory, Pei-Ling Tan and Koh (2017) posit that a classroom (an element in their framework) can be considered as a microsystem, constructed within time as part of the chronosystem. That is, activities and interactions in the classroom can be cumulative and change over time. Concretely, the following three interactions emerge in the classroom (PeiLing Tan \& Koh, 2017, pp. 5-6; see Figure 1):

- Interactions between educators and content: "the process by which the educator weaves together content knowledge (the 'what' of teaching), pedagogical knowledge (the 'how' of teaching), and pedagogical content knowledge (the blending of 'how' and 'what') to design the content that best facilitates student learning"3;

- Interactions between learners and educators: "enactment of teaching and learning";

- Interactions between learners and content: "students' interactional engagement in the learning experiences and with the learning content, as designed and facilitated by the educator." Importantly, this interaction also includes interactions between learners and covers more than just individual learning experiences with content.

Compared to the other frameworks, including Zimmermann and colleagues (2007) and the activity-based computing framework (e.g., Bardram, 2005), Pei-Ling Tan and Koh's (2017) lens seems to provide key information for researchers and practitioners of collaboration analytics. It illustrates relations between entities (i.e., teachers, learners, content), time, location (i.e., the classroom), and activity (i.e., collaboration processes). Despite a lack of empirical evidence, it acknowledges the

\footnotetext{
${ }^{3}$ These types of knowledge can also be differentiated with different names: "subject-specific content knowledge, subject-specific pedagogical content knowledge, and subject-unspecific psychological-pedagogical knowledge" (Kunter et al., 2013, p. 806).
}

ISSN 1929-7750 (online). The Journal of Learning Analytics works under a Creative Commons License, Attribution - NonCommercial-NoDerivs 3.0 Unported (CC BY-NC-ND 3.0) 
changeability of context (in line with our conceptualization) and comprehensively lays out its essential elements. It also depicts the specific context in which both instruction and collaborative learning take place. In doing so, it provides useful information that may help to create supportive collaborative learning environments (Buckingham Shum \& Ferguson, 2012). For these reasons, this paper applies Pei-Ling Tan and Koh's (2017) lens as the main framework to explore factors related to each relationship between entities (see Figure 1). This does not exclude the possibility that more appropriate frameworks might exist beyond our knowledge. This paper is also based on work by Kovanović, Joksimović, Gašević, Halata, and Siemens (2017). They classify learning content according to its producers: data from instructors (e.g., lecture recordings), data from publishers (e.g., textbooks), and data from students (e.g., social media posts). To these categories, we would add data from analytics, since analytics results are a further source of students' learning.

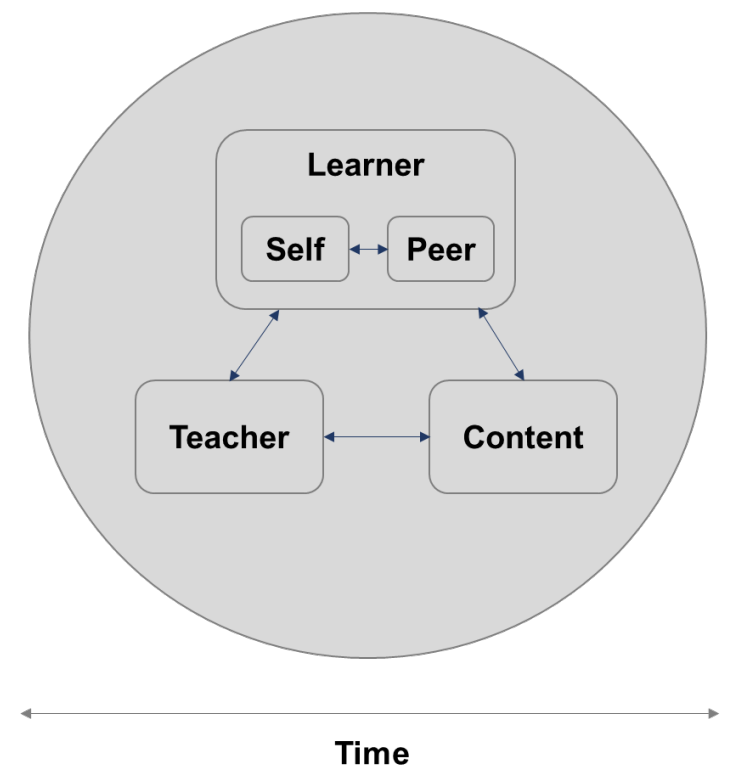

Figure 1. One example of a comprehensive framework to describe a classroom. Adapted from "Situating learning analytics pedagogically: Towards an ecological lens," by J. Pei-Ling Tan \& E. Koh, 2017, Learning: Research and Practice, 3(1), p, 5. Copyright 2017 by Informa UK Limited.

\section{Factors Contributing to Collaboration Analytics}

As stated earlier, according to Pei-Ling Tan and Koh's (2017) lens, the classroom can be depicted as a microsystem where interactions among content, students, and teachers co-exist and change over time as part of the chronosystem. Based on this framework, we suggest a list of potential factors to be considered when implementing collaboration analytics in classroom settings.

\subsection{Time}

Time-related factors can be considered, such as time points (i.e., when to measure students' collaboration process) or periods (i.e., how long certain student collaboration activities last), because the learning process consists of sequential blocks of temporal states (Reimann, 2009; Winne \& Baker, 2013). Moreover, characteristics of collaboration, such as coordination between group members, can differ over time. Thus, the collected process or performance data can differ over time, even when the collaboration modalities remain the same. For example, Järvelä, Malmberg, Haataja, Sobocinski, and Kirschner (in press) illustrate that students' socioemotional interactions increase during the initial stages of collaborative learning, because they are intertwined with cognitive interactions (Malmberg et al., 2019). Their results indicate that coordination facilitates good collaboration (Isohätälä, Järvenoja, \& Järvelä, 2017, as cited in Malmberg et al., 2019). If the frequency of socioemotional interaction is measured at this early phase and hastily judged to represent the overall characteristics of the group, students' collaboration will be misrepresented. Therefore, it is worth examining how each relationship in the group learning process unfolds over time.

Recently, Wiltshire and colleagues (2019, p. 143) investigated bodily movement coordination within teams over time by examining their emergent "cross-wavelet coherence" in a complex, computer-based collaborative problem-solving process. Here, cross-wavelet coherence is the proxy variable for a team's level of coordination. It was computed from captured behaviours such as "shifting of the legs" and ranged between zero and one in the time series (p. 145). According to the authors, 
zero means no coordination, while one means absolute coordination. They found that average cross-wavelet coherence has a U-shaped trajectory over time, which is comparable to Tuckman's team development model (cross-indexing team effectiveness and time; OERservices, n.d.; Tuckman \& Jensen, 1977; Wilshire et al., 2019). Wiltshire and colleagues (2019) show that a higher coherence trajectory is (on average) associated with better team performance, whereas a lower coherence trajectory is associated with worse team performance. Another point of contrast between low- and high-performing groups is stability; topperforming groups exhibit more stable coherence trajectories than low-performing groups. Overall, these results suggest that coordination when solving complex and dynamic problems varies over time depending on task demands (Funke, 2010; Wiltshire et al., 2019).

Time can be particularly crucial to analyzing linguistic interactions during collaboration because talk is a sequentially organized action (Silverman, 2014). For example, Dowell, Nixon, and Graesser (2019) examine disparate social roles using the methodology of group communication analysis, which applies computational linguistics to the sequential investigation of online group interactions. Their approach includes the analysis of the degree of relatedness between two variables given their time interval. Furthermore, the researchers constructed six dimensions (e.g., social impact) for the analysis; accordingly, linguistic patterns concerning "coordination and cohesion" represent participants' social roles in the discussions, offering insights such as the finding that the quality of communication is more pivotal to individuals' and groups' success than the quantity (p. 1007).

Despite being only indirectly relevant to the classroom setting, another worthwhile contribution to uncovering the importance of time during collaboration comes from De Boeck and Scalise (2019). They examined US students' results on the collaborative problem-solving skills assessment in the 2015 cycle of the OECD's Programme for International Student Assessment, exploring the relationships between actions, performance, and time. They found that the correlations between actions, time, and performance are all negative. That is, the more actions students perform, the worse their performance, but the faster their speed - presumably due to "an impulsive and fast trial-and-error style" by such test-takers (De Boeck \& Scalise, 2019, p. 6). Going beyond the individual level, researchers have attempted to extend this relationship between time, actions, and performance to the team level (e.g., Hernández-García, Acquila-Natale, Chaparro-Peláez, \& Conde, 2018), but more research is needed.

\subsection{Relationship between Teachers and Content}

Many previous studies assert the importance of teachers for the effectiveness of collaborative learning (Gillies, Ashman, \& Terwel, 2008; Kaendler et al., 2015). In this paper, we define teachers as people who play different roles: "(1) envision the lesson, (2) enable collaboration, (3) encourage students, (4) ensure learning, and (5) evaluate achievement" (Urhahne, Schanze, Bell, Mansfield, \& Holmes, 2010, p. 221). Furthermore, teachers should (6) reflect and inquire about their teaching practices via a process of teacher inquiry (Clarke \& Erickson, 2003). In carrying out these roles, teachers can be either analytics users or analytics producers, such as when monitoring learning processes and outcomes. They can also be data sources when it is their actions that are analyzed. Nevertheless, teachers tend to be neglected in the field of collaboration analytics and primarily considered to be users, not producers or data sources (McCoy \& Shih, 2016).

To understand teachers' role in each relationship and figure out which teacher-related factors need to be considered, we first discuss teachers' tasks and roles in collaboration, based on the Implementing Collaborative Learning in the Classroom (ICLC) framework by Kaendler and colleagues (2015; see Figure 2). The ICLC framework identifies teachers' roles and required competencies in three phases of collaborative learning: "a pre-active phase, an inter-active phase, and a post-active phase" (Kaendler et al., 2015, p. 508). The pre-active phase is for designing teaching and learning, while the other two phases cover the teacher-students or students-content relationships. In the current subsection, we address the pre-active phase, before turning to the other two phases in subsequent subsections.

In the pre-active phase, teachers plan and design how to implement collaborative classes by interweaving "content knowledge" (what to teach), "pedagogical knowledge" (how to teach), and "pedagogical content knowledge" (the mix of how and what of teach) (Pei-Ling Tan \& Koh, 2017, p. 6). Using all of their knowledge, teachers set learning goals and then identify characteristics likely to affect collaboration in the classroom, such as students' prior knowledge or experiences (Kaendler et al., 2015). Based on these characteristics, structures for collaborative lessons are predefined as lesson plans, scripts, or learning designs (Kaendler et al., 2015; Lockyer, Heathcote, \& Dawson, 2013). Likewise, task instructions, learning materials, and group formation schemes are planned and designed (Kaendler et al., 2015).

The activities and materials teachers use at this stage can be raw materials for collaboration analytics as well. For example, analyzing lesson plans makes it possible to examine how teachers design collaborative lessons using their content and pedagogical knowledge. Despite its focus on collaborative problem-solving, Cukurova and colleagues' (2018) taxonomy can be utilized here; it involves six interrelated domains at the same level: technology, characteristics of collaborative problemsolving, participants' abilities, group features, problem features, and other factors. They emphasize that these are not clear-cut 
categories. Nevertheless, the suggested taxonomy makes it possible to examine how teachers define learning goals and recognize classroom situations, and so on.
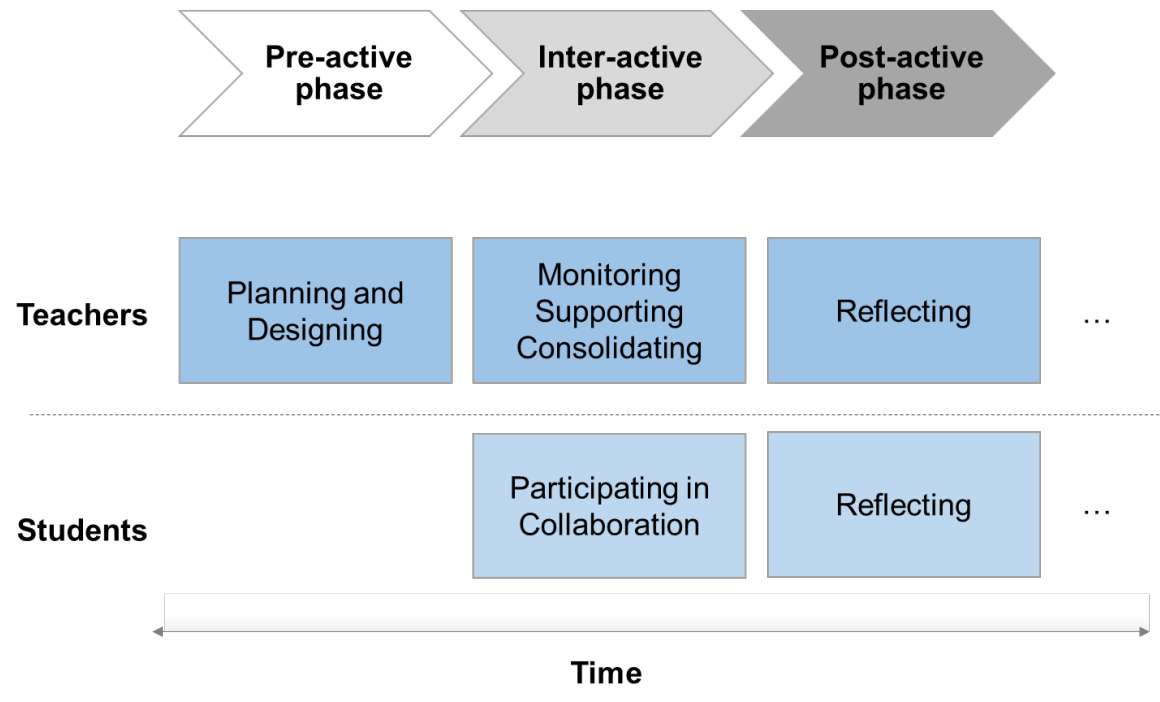

Figure 2. The three phases of collaborative learning and actions taken by each participating actor.

Adapted from "Teacher competencies for the implementation of collaborative learning in the classroom:

A framework and research review" by C. Kaendler, M. Wiedmann, N. Rummel, \& H. Spada, 2015,

Educational Psychology Review, 27, p. 508. Copyright 2015 by Springer Nature Switzerland AG.

Another piece of data for collaboration analytics is learning design, namely "the sequence of learning tasks, resources, and supports that a teacher constructs for students over part of, or the entire, academic semester" (Lockyer et al., 2013, pp. 14411442). It provides teachers with a broader picture of "pedagogical actions" than a lesson plan, which details each "instructional event" (Lockyer et al., 2013, p. 1442). No matter how teachers structure learning designs, they should include the following essential elements: key actors, teaching and learning tasks, resources for activities, and the sequence of activities (Lockyer et al., 2013). Thus, learning designs make it possible to analyze how teachers perceive collaborative classrooms and aid them in reflecting on their instructional designs and plans in the long term.

Although it is not related to collaborative classes, Nguyen, Rienties, and Toetenel (2017) provide an example of analyzing learning activities based on learning designs. They illustrate the variance in the time allotted for different activities over 32 course weeks in 24 modules of the Open University, UK (Nguyen et al., 2017). They start by categorizing learning activities into six types (e.g., assimilative: paying attention to information) with reference to Rienties and Toetenel (2016). Suppose that specific collaborative activities can be categorized and analyzed in terms of how they are interwoven over time, during a series of weeks, or even longer, using collaboration analytics. The collected data would be another source to compare to students' achievement, thus helping to determine how teachers convey content in collaborative classes over the long term.

\subsection{Relationship between Teachers and Students}

\subsubsection{Interactive Phase (Monitoring, Supporting, Consolidating)}

Providing timely support to students is one of teachers' roles during collaboration (Kaendler et al., 2015; van Leeuwen, van Wermeskerken, Erkens, \& Rummel, 2017), as well as a fundamental aim of learning analytics (Kovanović et al., 2017). Although teachers make thorough plans for students' collaboration and respond to students' questions during collaboration, students are not likely to actively regulate their learning and create new knowledge using their metacognition without sufficient support from teachers (Avezado \& Cromely, 2004; Kaendler et al., 2015; King, 2008). In turn, collaboration involving a lack of teacher support will be of low quality, partly because of the broad influence of metacognition ${ }^{4}$ on collaboration processes (e.g., in the process of "oral communication of information"; Flavell, 1979, p. 906).

\footnotetext{
${ }^{4}$ Metacognition can be extended to interactive situations (i.e., social metacognition), and students' "reciprocal scaffolding and greater motivation" benefit from social metacognition (Chiu \& Kuo, 2009, p. 14). Goos, Galbraith, and Renshaw (2002, p. 193) present evidence in which a small group of students failed at a problem-solving task due to poor "engagement with each other's thinking" within the team, which led to suboptimal metacognitive decisions at the team level.
}

ISSN 1929-7750 (online). The Journal of Learning Analytics works under a Creative Commons License, Attribution - NonCommercial-NoDerivs 3.0 Unported (CC BY-NC-ND 3.0) 
Furthermore, there are reasonable theoretical considerations suggesting that individual accountability within teams decreases as a result of teachers' lack of monitoring, which in turn increases social loafing (Johnson \& Johnson, 2008). Thus, teachers should monitor students' interactions and provide explicit guidance, such as letting students know their mistakes or asking questions (Kaendler et al., 2015). At this stage, the interactive phase of Figure 2, teachers should also promote psychological safety in the group and "ensure learning gain[s]" by consolidating students' results at the end (Kaendler et al., 2015, p. 509).

These necessary actions by teachers can be illuminated (i.e., what/how/when teachers engage in such actions) through collaboration analytics. For instance, van Leeuwen and colleagues (2017) scrutinize a teacher's log files, which include mouse and keyboard operations for sending messages (interventions), as well as eye movements. In doing so, they clarify the teacher's strategies for supporting collaboration and distributing attention during class.

Prieto and colleagues (2016, p. 150) likewise analyzed teachers' actions, after defining teaching practices during collaboration as "orchestration" ${ }^{5}$ based on Dillenbourg and colleagues (2009). Using multimodal wearable sensors and machine-learning techniques, they provide graphs of orchestration in a collaborative classroom. They find that both the actual enactment of teaching and the automatically analyzed model differ from the lesson plan due to the fluidity of activities and interactions in the classroom itself. If data from teachers in the interactive phase of Figure 2 are collected and accumulated as in the examples above, they can be compared with students' learning outcomes. The results of these comparisons can then aid teachers' reflection during the following phase or be utilized in future teacher training.

\subsubsection{Post-Active Phase (Reflecting)}

After the interactive phase (i.e., monitoring, supporting, consolidating during class), in the post-active phase of Figure 2, teachers contemplate the entire process and outcomes of students' collaboration, comparing them with the planned learning goals, objectives, and activities (Kaendler et al., 2015). Based on the collected data, teachers can verify the effects of their teaching and instructional design and think about alternative strategies (Kaendler et al., 2015; Santagata, Zannoni, \& Stigler, 2007). They also reflect on the students' and their own behaviours during collaboration.

From a critical perspective, teachers' "reflection-on-action" (i.e., before/after a given event) can be differentiated from "reflection-in-action" (i.e., thinking about what they are doing very quickly in real time) (Kaendler et al., 2015, p. 526; Schön, 1983). Teachers' reflection-in-action may be interrupted because numerous factors change rapidly in class, imposing high demands on teachers (van Leeuwen et al., 2017). Given its imperceptibility due to the interconnectedness with action, reflection-in-action can be explored only with teachers' actions (Bright, 1992). By contrast, during reflection-on-action, teachers can concentrate on their experiences with less interference (Kaendler et al., 2015), which is likely to be investigated separately.

Indeed, analyzing how teachers reflect on students' collaboration and interpret learning outcomes and data in the postactive phase (i.e., reflection-on-action; see Figure 2) is necessary (van Leeuwen et al., 2017) because such analysis can help teachers improve their subsequent sense-making and decision-making. A gap often exists between the data and students' actual changes, and teachers' sense-making and decision-making should be well executed in order to fill in this gap, although rapid changes in students' learning process may be expected once teachers transform data (e.g., into metrics on a dashboard) and think about the overall situation (Lockyer et al., 2013; van Leeuwen et al., 2017).

By now, several studies have explored teachers' reflection, sense-making, and decision-making when using collaboration analytics (Sergis \& Sampson, 2017; van Leeuwen et al., 2017). Of these, van Leeuwen and colleagues (2017) provide an example from a virtual collaborative class. They demonstrate two intervention cases and one non-intervention case in a teacher's recorded actions. Regarding the non-intervention case, the teacher stated in a subsequent interview that they had "deliberately refrained from intervening." Although the analytics results recommended intervention, the teacher judged that the students' work was appropriate (van Leeuwen et al., 2017, p. 53). These types of examples should be investigated more deeply.

\subsection{Relationship between Students and Content}

The last relationship concerns interactions between students' collaboration and learning process and the learning content (PeiLing Tan \& Koh, 2017). It refers to students' participation in collaboration activities consisting of "learning content" and "learning experiences" planned and facilitated by teachers and encompasses peer-to-peer interaction within groups (Pei-Ling Tan \& Koh, 2017, p. 6). One easily identifiable example of this relationship is problem-based learning classes involving specific content for collaboration (e.g., problem cases) and groups of students discussing the content collaboratively, such as those discussed by Jang and Park (2016). They observed medical school students in a collaborative learning environment in which students solved clinical cases together on a weekly basis. Interestingly, their results confirmed that collaborative

\footnotetext{
5 "the process of productively coordinating supportive interventions across multiple learning activities occurring at multiple social levels"
} (Dillenbourg et al., 2009; as cited in Prieto et al., 2016, p. 150).

ISSN 1929-7750 (online). The Journal of Learning Analytics works under a Creative Commons License, Attribution - NonCommercial-NoDerivs 3.0 Unported (CC BY-NC-ND 3.0) 
performance (i.e., peer evaluation) was influenced by students' traits assessed using the Temperament and Character Inventory by Cloninger, Svrakic, and Przybeck (1993) (e.g., harm avoidance was negatively associated with engagement in collaborative learning).

When including correlations with personalities as above, it seems that multiple collaboration processes (both interpersonal and intrapersonal) occur and interact dynamically (Stewart et al., 2019). Some of them are emotion/task co-regulation, establishing common ground and perspective-taking, building rapport, asking questions, providing peer feedback, elaborating and integrating ideas, and negotiation (Dowell, Lin, Godfrey, \& Brooks, 2019; Dowell et al., 2019; OECD, 2017; Scoular \& Care, 2020; Stewart et al., 2019). The interrelations among dynamic processes are critical for successful collaboration (Gašević, Joksimović, Eagan, \& Shaffer, 2019). So far, researchers have studied collaboration processes and models, alongside factors influencing the processes and outcomes (e.g., Fiore \& Kapalo, 2017; Gašević et al., 2019; Hesse, Care, Buder, Sassenberg, \& Griffin, 2015; OECD, 2017; Scoular \& Care, 2020).

However, many unanswered questions remain, such as the extent to which external/internal conditions influence learners' outcomes or operations like synthesizing knowledge in the online forum (Gašević, Dawson, \& Siemens, 2015). Examining these internal/external factors using collaboration analytics has merit, since it helps identify the root causes of students' learning and changes during collaboration beyond simplistic predictions, diagnoses, and descriptions. Clarifying the effects of various conditions can be beneficial for the validity of results and their consequences for research and practice (Gašević et al., 2015; Gašević, Dawson, Rogers, \& Gasevic, 2016). For instance, knowledge of how learners' interaction patterns vary by demographic variables can be used to inform instructional designs that promote equity in online learning spaces (Baker, Dee, Evans, \& John, 2018; Lin, Dowell, Godfrey, Choi, \& Brooks, 2019). This paper categorizes internal/external factors into three dimensions: social, cognitive, and affective (Ludvigsen, 2016; Nieswandt, McEneaney, \& Affolter, 2020); however, the suggested classification is not exhaustive.

Turning first to the social dimension, we can think about factors that affect "interdependence" (Johnson \& Johnson, 2008, p. 33). For example, learners' language and ethnicity can be taken into account. In a recent paper, Yow and Lim (2019) report that pairs with the same second language outperformed other pairs in insight problem-solving tasks, but not in divergentthinking tasks. Notably, the pairs with different second languages collaborated more (average turns per minute) and communicated more (average utterances) during the divergent thinking tasks. Considering the effect of socioeconomic status (SES) on peer feedback, Choi, Dowell, Brooks, and Teasley (2019) find that learners from high-SES nations in massive open online courses (MOOCs) are likely to give learners from low-income countries less formal and more emotional feedback, but offered more formal and less emotional feedback to learners from medium-income countries. Gender can also be related to learners' interaction patterns, particularly communication. Lin and colleagues (2019) attest that female students tend to engage in relevant discourse that moves the conversation further more than male students, contradicting the gender stereotype that female students are less active and more submissive in group interactions.

Concerning the cognitive dimension, first, data literacy can influence students' reflection using analytic tools. In a study by Chen and colleagues (2018), a participant said "CanvasNet [the name of the analytics tool studied] was actually interesting ... I can check how many [times I interacted] with a person," while another student confessed that "for CanvasNet I tried once or twice, but I did not really get it. I thought it was not quite easy to look at" (p. 26). Additionally, prior knowledge, problemsolving $^{6}$, and interpersonal skills can affect collaboration processes and outcomes. Some students have difficulties with collaborative learning and cannot perform well due to insufficient problem-solving schemas or interpersonal skills (Hagemann \& Kluge, 2017; Le, Janssen, \& Wubbels, 2018). Variation in prior domain experience among students can be considered as well. Stewart, Amon, Duran, and D'Mello (2020) found that variance in prior experience with formal physics courses was the strongest predictor of task scores at the team level, albeit non-significant. This finding may be due to more difficulty that the teams had, which originated from coordinating the differences in their prior domain experience. Students' metacognition is also crucial; through a combination of social network analysis and epistemic network analysis, Gašević and colleagues (2019) demonstrate the positive relationship among students' performance, metacognitive monitoring, and learning aligned with a MOOC's course standards.

Lastly, Kelly and Barsade (2001, p. 99) identify several factors regarding the affective dimension, that is, "moods, emotions, sentiments, and emotional intelligence." According to them, these individual characteristics merge into a group's affective composition through explicit and implicit processes and under the influence of the affective context (e.g., emotional norms within the group). This group emotion, in turn, can influence outcomes like group cooperativeness or performance and can also feed back into the group emotion at a later point. For instance, rapport within teams (e.g., Morrison, 2009) influences

\footnotetext{
${ }^{6}$ Collaborative problem-solving schemas can include knowledge about the "problem type" (e.g., strategies), "procedural operators for how to solve a problem type" (Nokes-Malach, Meade, \& Morrow, 2012, p. 38), and "interpositional knowledge" (i.e., "an individual understanding concerning the tasks and duties of all team members, in order to develop an understanding about the impact of own actions on the actions of other team members and vice versa"; Hagemann \& Kluge, 2017, p. 3).
}

ISSN 1929-7750 (online). The Journal of Learning Analytics works under a Creative Commons License, Attribution - NonCommercial-NoDerivs 3.0 Unported (CC BY-NC-ND 3.0) 
collaboration processes (e.g., receiving support from colleagues) and outcomes. Another example is collective orientation within teams, which refers to "the propensity to work in a collective manner in team settings" (Driskell, Salas, \& Hughes, 2010, p. 317). This can be understood as an attitude or preference, not a trait that a team possesses at the start or an outcome (Driskell et al., 2010). However, it can also represent "new inputs to subsequent processes and outcomes" (Marks, Mathieu, \& Zaccaro, 2001, p. 358). Hagemann and Kluge (2017) suggest that collective orientation induces high coordination within teams in problem-solving situations; consequently, it positively impacts teams' decision-making and performance. Trust can also positively affect teamwork engagement. Zhang, Meng, de Pablos, and Sun (2019) show that participants in teams who worked together knew each member's capabilities (i.e., what they can do well), but did not share strong social ties. That is, their affective trust was lower than their cognitive trust (see also Webber, 2008) 7 .

\section{Conclusion with Future Research Agenda and Possible Challenges}

Learning analytics technology is advancing and being extended to analyses of students' collaboration. Depending on the type of analytics implemented, such techniques run the risk of not fully capturing the educational contexts where real-world collaboration takes place in a sufficiently comprehensive manner (e.g., when the users must make decisions without sufficient contextual information based on data collected without predefined models). Thus, taking a comprehensive view when applying collaboration analytics is imperative, because knowledge about collaboration is always situated in a specific context, and students can learn as a result of interactions within this context. Moreover, the understanding of contexts in collaboration analytics influences students' learning because it is related to the question of how and what to measure. There are many concepts and frameworks for collaboration and collaboration analytics. They each have a different focus and theoretical perspective (e.g., whether or not to include problem-solving as part of collaboration), so different elements must be included in any view.

As an initial step, this paper restricts the context to a collaborative classroom setting (whether virtual or physical). Based on considering multiple models yet with a focus on Pei-Ling Tan and Koh's (2017) ecological lens, this paper regards the context as the place where three interactions co-emerge among students, teachers, and content, integrally interwoven with time. It also suggests several points regarding each dimension that should be kept in mind when utilizing collaboration analytics. In summary, time-related variables (e.g., time points and periods) should be carefully considered. Data collected from teachers by delving into teacher-related interactions can also be valuable for achieving high-quality results. As one way of examining teachers' data, this paper explores teachers' roles and competencies during collaborative classes, as explained in the ICLC framework by Kaendler and colleagues (2015). Furthermore, it proposes considering the social, cognitive, and affective dimensions of students' collaboration when exploring the relationship between students and content (including collaboration between peers). While the proposed factors are not exhaustive, this paper provides suggestions for researchers and teachers to reflect on the comprehensive context in collaborative classes.

Challenges for future research and practice remain. First, some technical challenges must be solved, such as difficulties incorporating mass data from different sources in a synchronized way (Shankar, Prieto, Rodríguez-Triana, \& Ruiz-Calleja, 2018, as cited in Joksimović et al., 2019), not overwhelming teachers and students with too much data that is ineffectively communicated (Ferguson \& Buckingham Shum, 2012), making latent variables visible (e.g., "mental regulation processes"; Järvelä et al., in press, p. 7), and appropriately modelling educational elements after data processing (De Laat \& Prinsen, 2014; Selwyn, 2019).

Second, various ethical challenges can be expected. As Selwyn $(2019$, p. 18) states, such challenges can be related to "power, control, and disparities in access and outcomes." For instance, implicit "data harvesting" can make students and teachers uncomfortable, since the educational field often handles sensitive personal data (Ferguson \& Buckingham Shum, 2012, p. 9). Also, data ownership issues can arise when the same data sources are shared with stakeholders with different access rights (Ndukwe \& Daniel, 2020). Furthermore, being "nudged" toward certain conduct can demotivate students and teachers (Knox, Williamson, \& Bayne, 2020, p. 42). Therefore, stable systems for collecting, streaming, and delivering data should be constructed (Shankar et al., 2018, as cited in Joksimović et al., 2019). Accountability on data collection, usage, and access should also be maintained (De Laat \& Prinsen, 2014; Ferguson \& Buckingham Shum, 2012). For example, data shareability agreements between stakeholders should come into increasing use (Ndukwe \& Daniel, 2020). The use of key actors' voices (e.g., students, teachers) should be reflected on to a greater extent to avoid privacy problems in collaboration analytics (Heath, 2014), and consent should be sought. In addition, newly emergent ethical challenges should be further scrutinized, such that the underlying algorithms to collect and process data can be inspected for the presence of biases or fatal defects (Smith, 2018).

\footnotetext{
${ }^{7}$ Trust is a multidimensional concept that can be divided into cognitive trust (i.e., "reliability, dependability, and competence") and affective trust (i.e., "care, concern, and emotional bonds"; Webber, 2008, p. 765).
}

ISSN 1929-7750 (online). The Journal of Learning Analytics works under a Creative Commons License, Attribution - NonCommercial-NoDerivs 3.0 Unported (CC BY-NC-ND 3.0) 
Another recommendation for future research concerns theoretical work to increase the degree of consensus on collaboration. That is, more theoretical research investigating collaboration in classroom settings is needed. As Wise and Shaffer (2015) argue, learning analytics researchers should proceed from theory, so we should first look for and create a solid theoretical foundation for collaboration. One suggestion is to break down collaborative learning situations in greater detail, as discussed by Graesser and colleagues (2018; e.g., collaborative problem-solving or learning). Alternatively, collaborative classes can be differentiated based on subject or course unit. It would also be beneficial for future studies of collaboration analytics to examine collaboration in classrooms with more specific criteria.

Table 1 summarizes the points that should be considered in future research endeavours based on the comprehensive model and specific suggestions presented in this paper.

Table 1. Specific suggestions based on the model by Pei-Ling Tan and Koh (2017)

\begin{tabular}{|c|c|c|}
\hline No & Dimension & Research agenda points \\
\hline 1 & Time & $\begin{array}{l}\text { - Consider time points and periods with respect to collaboration processes and vary them in the } \\
\text { analysis at different levels (i.e., individual/group). However, practise caution when making } \\
\text { conclusions about the relationships between time, actions, and performance. For instance, } \\
\text { according to Bolsinova, de Boeck, and Tijmstra (2017), the relationship between time spent } \\
\text { and response accuracy in educational assessments does not fully capture the relationship } \\
\text { between speed and ability, since time-related differences can arise for different reasons, such } \\
\text { as using different strategies to solve the problem (Bolsinova et al., 2017) or aberrant behaviour, } \\
\text { rather than ability (Bolsinova \& Molenaar, 2018). }\end{array}$ \\
\hline
\end{tabular}

2 Relationship - Organize information about teachers' design of collaborative learning (e.g., lesson plans). In between teachers their instruction, teachers often consider different design components, such as class weeks; and content collecting and analyzing this information about teachers' design can make their conceptualization of collaborative courses explicit (Wise \& Jung, 2019). For example, analyzing lesson plans can show how teachers apply content and pedagogical knowledge. Taxonomies such as the one proposed by Cukurova and colleagues (2018) can be used, for example, to visualize teachers' allocation of group roles8 in collaborative classes.

3 Relationship - Collect data about teachers' actions in both the interactive phase (i.e., monitoring, supporting, between teachers consolidating) and the post-active phase (i.e., reflection; see Figure 2). For example, one might and students analyze teachers' reflective journals or conduct separate post-interviews.

- Continue to distinguish among different teaching activities, using speech analysis, for example. In terms of difficulties associated with such differentiation, Prieto and colleagues (2016, p. 154) report that certain errors (e.g., "the activities of monitoring students' work and providing repairs when one of them asks a question, which flow very fluidly into each other") were more frequent than others when analyzing teachers' data.

- If possible, simultaneously measure and compare teachers' actions and students' performance or levels of collaboration (in line with the perspective of teaching and learning analytics; Sergis \& Sampson, 2017). This makes it possible to evaluate the quality of teachers' actions. For example, the level of coordination or communication frequency within teams can be measured and compared depending on the level of teacher guidance. Teachers' discourse can be another topic of further research; that is, changes in students' actions during collaboration can be measured and analyzed alongside the specific discourses that teachers use, leveraging techniques such as natural language processing.

\begin{tabular}{|c|c|}
\hline $\begin{array}{l}\text { Relationship } \\
\text { between students } \\
\text { and content } \\
\text { (including peer } \\
\text { collaboration) }\end{array}$ & $\begin{array}{l}\text { - Consider various external/internal conditions that influence learners' collaboration processes } \\
\text { and outcomes (social, cognitive, and affective dimensions). A course unit or subject can be } \\
\text { suggested instead of generalized models when conducting such research. Despite being from } \\
\text { the related field of students' academic success and learning analytics, Gašević and colleagues } \\
\text { (2016) report results highlighting the superiority of course-specific models in terms of } \\
\text { providing better insight into the factors that influence students' academic success. }\end{array}$ \\
\hline
\end{tabular}

${ }^{8}$ Group roles refer to "the extent to which participant roles are encouraged by activity design" and can be classified into three types: roles distributed by teachers, roles encouraged by teachers (e.g., in jigsaw working), and unplanned roles (i.e., students have the freedom to distribute roles themselves) (Cukurova et al., 2018, p. 331).

ISSN 1929-7750 (online). The Journal of Learning Analytics works under a Creative Commons License, Attribution - NonCommercial-NoDerivs 3.0 Unported (CC BY-NC-ND 3.0) 
It might only be possible for research to adopt such considerations with respect to the analysis of small groups or a small number of course units due to time and resource limitations. Nevertheless, a comprehensive framework that includes time, learning content, and interactions between students and teachers and among students - as proposed in this article - should either (1) not be forgotten when implementing collaboration analytics in these conditions or (2) at least be discussed if implementation is not possible. Considering a comprehensive framework makes it possible to reduce measurement errors and provide more accurate and actionable information to stakeholders, thus increasing the quality of collaboration and its effectiveness for learning. Although this article focuses on collaborative classroom settings, it should be noted that collaboration can take place in other settings outside of education, such as workplaces.

Please note that this paper has limitations regarding the selection and review of the literature. Although key studies and frameworks were considered as the foundation for this article, no attempt was made to systematically review the literature. Nevertheless, we believe that awareness of the important topic of comprehensive models should first be strengthened, which might serve as a starting point for further studies with original data and for systematic reviews. We hope that future studies build and expand upon this paper by identifying comprehensive approaches for diverse collaborative settings in the foreseeable future.

\section{Declaration of Conflicting Interests}

The authors declared no potential conflicts of interest with respect to the research, authorship, and/or publication of this article.

\section{Funding}

The authors declared no financial support for the research, authorship, and/or publication of this article.

\section{References}

Avezado, R., \& Cromley, J. G. (2004). Does training on self-regulated learning facilitate students' learning with hypermedia? Journal of Educational Psychology, 96(3), 523-535. https://doi.org/10.1037/0022-0663.96.3.523

Baker, R., Dee, T., Evans, B., \& John, J. (2018, March). Bias in Online Classes: Evidence from a Field Experiment (Institute for Economic Policy Research Working paper No 18-055). https://siepr.stanford.edu/sites/default/files/publications/18055.pdf

Bardram, J. E. (2005). Activity-based computing: Support for mobility and collaboration in ubiquitous computing. Personal and Ubiquitous Computing, 9, 312-322. https://doi.org/10.1007/s00779-004-0335-2

Bolsinova, M., de Boeck, P., \& Tijmstra, J. (2017). Modelling conditional dependence between response time and accuracy. Psychometrika, 82, 1126-1148. https://doi.org/10.1007/s11336-016-9537-6

Bolsinova, M., \& Molenaar, D. (2018). Modeling nonlinear conditional dependence between response time and accuracy. Frontiers in Psychology, 9(1), 1-12. https://doi.org/10.3389/fpsyg.2018.01525

Bright, B. P. (1992). Reflection and knowledge: Aspects and problems. In P. Armstrong \& N. Miller (Eds.), Knowledge and performance: The politics of adult/continuing education (pp. 42-47). Proceedings of the 21st Annual SCUTREA Conference.

Bronfenbrenner, U. (1979). The Ecology of Human Development: Experiments by Nature and Design. Cambridge, MA: Harvard University Press.

Brown, G., Bull, J., \& Pendlebury, M. (1997). Assessing Student Learning in Higher Education. London: Routledge.

Brown, J. S., Collins, A., \& Duguid, P. (1989). Situated cognition and the culture of learning. Educational Researcher, 18(1), 32-42. https://doi.org/10.3102/0013189X018001032

Buckingham Shum, S., \& Ferguson, R. (2012). Social learning analytics. Educational Technology \& Society, 15(3), 3-26. https://www.jstor.org/stable/jeductechsoci.15.3.3

Chen, B., Chang, Y-H., Ouyang, F., \& Zhou, W. (2018). Fostering student engagement in online discussion through social learning analytics. The Internet and Higher Education, 37(1), 21-30. https://doi.org/10.1016/j.iheduc.2017.12.002

Chiu, M. M., \& Kuo, S. W. (2009). From metacognition to social metacognition: Similarities, differences, and learning. Journal of Education Research, 3(4), 1-19.

Choi, H., Dowell, N., Brooks, C., \& Teasley, S. (2019). Social comparison in MOOCs: Perceived SES, opinion, and message formality. Proceedings of the Ninth International Conference on Learning Analytics and Knowledge (LAK '19), 4-8 March 2019, Tempe, AZ, USA (pp. 160-169). New York: ACM. https://doi.org/10.1145/3303772.3303773

Chounta, I.-A., \& Avouris, N. (2016). Towards the real-time evaluation of collaborative activities: Integration of an automatic rater of collaboration quality in the classroom from the teacher's perspective. Education and Information Technologies, 21, 815-835. https://doi.org/10.1007/s10639-014-9355-3 
Clarke, A., \& Erickson, G. (Eds.). (2003). Teacher Inquiry: Living the Research in Everyday Practice. London: RoutledgeFalmer.

Cloninger, C. R., Svrakic, D. M., \& Przybeck, T. R. (1993). A psychobiological model of temperament and character. Archives of General Psychiatry, 50(12), 975-990. https://doi.org/10.1001/archpsyc.1993.01820240059008

Cukurova, M., Luckin, R., \& Baines, E. (2018). The significance of context for the emergence and implementation of research evidence: The case of collaborative problem-solving. Oxford Review of Education, 44(3), 322-337. https://doi.org/10.1080/03054985.2017.1389713

Darling, N. (2007). Ecological systems theory: The person in the center of circles. Research in Human Development, 4(3-4), 203-217. https://doi.org/10.1080/15427600701663023

Dascalu, M., Trausan-Matu, S., McNamara, D. S., \& Dessus, P. (2015). ReaderBench: Automated evaluation of collaboration based on cohesion and dialogism. International Journal of Computer-Supported Collaborative Learning, 10, 395-423. https://doi.org/10.1007/s11412-015-9226-y

De Boeck, P., \& Scalise, K. (2019). Collaborative problem solving: Processing actions, time, and performance. Frontiers in Psychology, 10, 1-9. https://doi.org/10.3389/fpsyg.2019.01280

De Laat, M., \& Prinsen, F. R. (2014). Social learning analytics: Navigating the changing settings of higher education. Research \& Practice in Assessment, 9, 51-60. http://www.rpajournal.com/dev/wp-content/uploads/2014/10/A5.pdf

Dey, A. (2001). Understanding and using context. Personal and Ubiquitous Computing, 5, 4-7. https://doi.org/10.1007/s007790170019

Dillenbourg, P., Järvelä, S., \& Fischer, F. (2009). The evolution of research on computer-supported collaborative learning: From design to orchestration. In N. Balacheff, S. Ludvigsen, T. de Jong, A. Lazonder, \& S. Barnes (Eds.), Technology-Enhanced Learning: Principles and Products (pp. 3-19). Amsterdam: Springer. https://doi.org/10.1007/978-1-4020-9827-7_1

Dowell, N., Lin, Y., Godfrey, A., \& Brooks, C. (2019). Promoting inclusivity through time-dynamic discourse analysis in digitally-mediated collaborative learning. In S. Isotani, E. Millán, A. Ogan, P. Hastings, B. McLaren, \& R. Luckin (Eds.), Artificial Intelligence in Education (pp. 207-219). AIED 2019. Lecture Notes in Computer Science, vol. 11625. Cham: Springer International Publishing. https://doi.org/10.1007/978-3-030-23204-7 18

Dowell, N., Nixon, T. M., \& Graesser, A. C. (2019). Group communication analysis: A computational linguistics approach for detecting sociocognitive roles in multiparty interactions. Behavior Research Methods, 51, 1007-1041. https://doi.org/10.3758/s13428-018-1102-z

Driskell, J. E., Salas, E., \& Hughes, S. (2010). Collective orientation and team performance: Development of an individual differences measure. Human Factors, 52(2), 316-318. https://doi.org/10.1177/0018720809359522

Echeverria, V., Martinez-Maldonado, R., \& Buckingham Shum, S. (2019). Towards collaboration translucence: Giving meaning to multimodal group data. Proceedings of the 2019 CHI Conference on Human Factors in Computing Systems (CHI '19), 4-9 May 2019, Glasgow, UK (pp. 1-16). New York: ACM. https://doi.org/10.1145/3290605.3300269

Ferguson, R., \& Buckingham Shum, S. (2012). Social learning analytics: Five approaches. Proceedings of the Second International Conference on Learning Analytics and Knowledge (LAK '12), 29 April-2 May 2012, Vancouver, BC, Canada (pp. 23-33). New York: ACM. http://doi.org/doi:10.1145/2330601.2330616

Fiore, S. M., \& Kapalo, K. A. (2017). Innovation in team interaction: New methods for assessing collaboration between brains and bodies using a multi-level framework. In A. A. von Davier, M. Zhu, \& P. C. Kyllonen (Eds.), Innovative Assessment of Collaboration (pp. 51-64). Cham: Springer International Publishing. https://doi.org/10.1007/978-3-31933261-1 4

Flavell, J. H. (1979). Metacognition and cognitive monitoring: A new area of cognitive-developmental inquiry. American Psychologist, 34(10), 906-911. https://doi.org/10.1037/0003-066X.34.10.906

Funke, J. (2010). Complex problem solving: A case for complex cognition?. Cognitive Processing, 11, 133-142. https://doi.org/10.1007/s10339-009-0345-0

Gašević, D., Dawson, S., Rogers, T., \& Gasevic, D. (2016). Learning analytics should not promote one size fits all: The effects of instructional conditions in predicting academic success. The Internet and Higher Education, 28, 68-84. https://doi.org/10.1016/j.iheduc.2015.10.002

Gašević, D., Dawson, S., \& Siemens. G. (2015). Let's not forget: Learning analytics are about learning. TechTrends, 59, 6471. https://doi.org/10.1007/s11528-014-0822-x

Gašević, D., Joksimović. S., Eagan, B. R., \& Shaffer, D. W. (2019). SENS: Network analytics to combine social and cognitive perspectives of collaborative learning. Computers in Human Behavior, 92, 562-577.

https://doi.org/10.1016/j.chb.2018.07.003 
Gillies, R. M., Ashman, A., \& Terwel, J. (Eds.). (2008). The Teacher's Role in Implementing Cooperative Learning in the Classroom. New York: Springer.

Goos, M., Galbraith, P., \& Renshaw, P. (2002). Socially mediated metacognition: Creating collaborative zones of proximal development in small group problem solving. Educational Studies in Mathematics, 49, 193-223. https://doi.org/10.1023/A:1016209010120

Graesser, A. C., Fiore, S. M., Greiff, S., Andrews-Todd, J., Foltz, P. W., \& Hesse, F. W. (2018). Advancing the science of collaborative problem solving. Psychological Science in the Public Interest, 19(2), 59-92.

https://doi.org/10.1177/1529100618808244

Haataja, E., Moreno-Esteva, E. G., Salonen, V., Laine, A., Toivanen, M., \& Hannula, M. S. (2019). Teacher's visual attention when scaffolding collaborative mathematical problem solving. Teaching and Teacher Education, 86, 1-15. https://doi.org/10.1016/j.tate.2019.102877

Hagemann, V., \& Kluge, A. (2017). Complex problem solving in teams: The impact of collective orientation on team process demands. Frontiers in Psychology, 8, 1-17. https://doi.org/10.3389/fpsyg.2017.01730

Heath, J. (2014). Contemporary privacy theory contributions to learning analytics. Journal of Learning Analytics, 1(1), 140149. https://doi.org/10.18608/jla.2014.11.8

Hernández-García, Á., Acquila-Natale, E., Chaparro-Peláez, J., \& Conde, M. Á. (2018). Predicting teamwork group assessment using log data-based learning analytics. Computers in Human Behavior, 89, 373-384. https://doi.org/10.1016/j.chb.2018.07.016

Hesse, F., Care, E., Buder, J., Sassenberg, K., \& Griffin, P. (2015). A framework for teachable collaborative problem solving skills. In P. Griffin \& E. Care (Eds.), Assessment and Teaching of 21st Century Skills: Methods and Approach (pp. 37 56). Dordrecht: Springer. https://doi.org/10.1007/978-94-017-9395-7 2

Isohätälä, J., Järvenoja, H., \& Järvelä, S. (2017). Socially shared regulation of learning and participation in social interaction in collaborative learning. International Journal of Education Research, 81, 11-24. https://doi.org/10.1016/j.ijer.2016.10.006

Jang, H. W., \& Park, S. W. (2016). Effects of personality traits on collaborative performance in problem-based learning tutorials. Saudi Medical Journal, 37(12), 1365-1371. https://doi.org/10.15537/smj.2016.12.15708

Järvelä, S., Malmberg, J., Haataja, E., Sobocinski, M., \& Kirschner, P. (in press). What multimodal data can tell us about the students' regulation of their learning process? Learning and Instruction.

https://doi.org/10.1016/j.learninstruc.2019.04.004

Johnson, D. W., \& Johnson. R. T. (2008). Social interdependence theory and cooperative learning: The teacher's role. In R. M. Gillies, A. Ashman, \& J. Terwel (Eds.), The Teacher's Role in Implementing Cooperative Learning in the Classroom (pp. 9-37). New York: Springer. https://doi.org/10.1007/978-0-387-70892-8 1

Joksimović. S., Kovanović, V., \& Dawson, S. (2019). The journey of learning analytics. HERDSA Review of Higher Education, 6, 37-63.

Kaendler, C., Wiedmann, M., Rummel, N., \& Spada, H. (2015). Teacher competencies for the implementation of collaborative learning in the classroom: A framework and research review. Educational Psychology Review, 27, 505536. https://doi.org/10.1007/s10648-014-9288-9

Kelly, J. R., \& Barsade, S. G. (2001). Mood and emotions in small groups and work teams. Organizational Behavior and Human Decision Processes, 86(1), 99-130. https://doi.org/10.1006/obhd.2001.2974

King, A. (2008). Structuring peer interaction to promote higher-order thinking and complex learning in cooperating groups. In R. M. Gillies, A. Ashman, \& J. Terwel (Eds.), The Teacher's Role in Implementing Cooperative Learning in the Classroom (pp. 73-91). New York: Springer. https://doi.org/10.1007/978-0-387-70892-8 4

Knight, S., Buckingham Shum, S., \& Littleton, K. (2013). Epistemology, pedagogy, assessment and learning analytics. Proceedings of the Third International Conference on Learning Analytics and Knowledge (LAK '13), 8-12 April 2013, Leuven, Belgium (pp. 75-84). New York: ACM. https://doi.org/10.1145/2460296.2460312

Knox, J. (2017). Data power in education: Exploring critical awareness with the "learning analytics report card." Television \& New Media, 18(8), 734-752. https://doi.org/10.1177/1527476417690029

Knox, J., Williamson, B., \& Bayne, S. (2020). Machine behaviourism: Future visions of "learnification" and "datafication" across humans and digital technologies. Learning, Media and Technology, 45(1), 31-45.

https://doi.org/10.1080/17439884.2019.1623251

Kovanović, V., Joksimović. S., Gašević, D., Halata, M., \& Siemens, G. (2017). Content analytics: The definition, scope, and an overview of published research. In C. Lang, G. Siemens, A. Wise, \& D. Gašević (Eds.), Handbook of Learning Analytics (1st ed., pp. 77-92). Society for Learning Analytics Research. https://doi.org/10.18608/hla17 
Kunter, M., Klusmann, U., Baumert, J., Richter, D., Voss, T., \& Hachfeld, A. (2013). Professional competence of teachers: Effects on instructional quality and student development. Journal of Educational Psychology, 105(3), 805-820. https://doi.org/10.1037/a0032583

Le, H., Janssen, J., \& Wubbels, T. (2018). Collaborative learning practices: Teacher and student perceived obstacles to effective student collaboration. Cambridge Journal of Education, 48(1), 103-122. https://doi.org/10.1080/0305764X.2016.1259389

Leontyev, A. N. (1978). Activity, Consciousness, and Personality. Englewood Cliffs, NJ, USA: Prentice Hall.

Lin, Y., Dowell, N., Godfrey, A., Choi, H., \& Brooks, C. (2019). Modeling gender dynamics in intra and interpersonal interactions during online collaborative learning. Proceedings of the Ninth International Conference on Learning Analytics and Knowledge (LAK '19), 4-8 March 2019, Tempe, AZ, USA (pp. 431-435). New York: ACM. https://doi.org/10.1145/3303772.3303837

Lockyer, L., Heathcote, E., \& Dawson, S. (2013). Informing pedagogical action: Aligning learning analytics with learning design. American Behavioral Scientist, 57(10), 1439-1459. https://doi.org/10.1177/0002764213479367

Ludvigsen, S. (2016). CSCL: Connecting the social, emotional and cognitive dimensions. International Journal of Computer-Supported Collaborative Learning, 11, 115-121. https://doi.org/10.1007/s11412-016-9236-4

Malmberg, J., Järvelä, S., Holappa, J., Haataja, E., Huang, X., \& Siipo, A. (2019). Going beyond what is visible: What multichannel data can reveal about interaction in the context of collaborative learning? Computers in Human Behavior, 96, 235-245. https://doi.org/10.1016/j.chb.2018.06.030

Marks, M. A., Mathieu, J. E., \& Zaccaro, S. J. (2001). A temporally based framework and taxonomy of team processes. The Academy of Management Review, 26(3), 356-376. https://doi.org/10.2307/259182

Martinez-Maldonado, R., Clayphan, A., \& Kay, J. (2013). Towards the integration of collaboration analytics and interactive surfaces. Proceedings of the International Conference on Interactive Tabletops and Surfaces (ITS '13), 6-9 October 2013, St. Andrews, UK (pp. 1-8). New York: ACM.

Martinez-Maldonado, R., Goodyear, P., Kay, J., Thompson, K., \& Carvalho, L. (2016). An actionable approach to understand group experience in complex, multi-surface spaces. Proceedings of the 2016 CHI Conference on Human Factors in Computing Systems (CHI '16), 7-12 May 2016, San Jose, CA, USA (pp. 2062-2074). New York: ACM. https://doi.org/10.1145/2858036.2858213

Martinez-Maldonado, R., Kay, J., Buckingham Shum, S., \& Yacef, K. (2019). Collocated collaboration analytics: Principles and dilemmas for mining multimodal interaction data. Human-Computer Interaction, 34(1), 1-50. https://doi.org/10.1080/07370024.2017.1338956

McCoy, C., \& Shih, P. (2016). Teachers as producers of data analytics: A case study of a teacher-focused educational data science program. Journal of Learning Analytics, 3(3), 193-214. https://doi.org/10.18608/jla.2016.33.10

Morrison, R. L. (2009). Are women tending and befriending in the workplace? Gender differences in the relationship between workplace friendships and organizational outcomes. Sex Roles, 60(1-2), 1-13. https://doi.org/10.1007/s11199-008-9513-4

Ndukwe, I. G., \& Daniel, B. K. (2020). Teaching analytics, value and tools for teacher data literacy: A systematic and tripartite approach. International Journal of Educational Technology in Higher Education, 17, 1-31. https://doi.org/10.1186/s41239-020-00201-6

Nguyen, Q., Rienties, B., \& Toetenel, L. (2017). Mixing and matching learning design and learning analytics. In P. Zaphiris \& A. Ioannou (Eds.), Learning and Collaboration Technologies. Technology in Education (pp. 302-316). Cham: Springer. https://doi.org/10.1007/978-3-319-58515-4_24

Nieswandt, M., McEneaney, E. H., \& Affolter, R. (2020). A framework for exploring small group learning in high school science classrooms: The triple problem solving space. Instructional Science, 48, 243-290.

https://doi.org/10.1007/s11251-020-09510-9

Nokes-Malach, T. J., Meade, M. L., \& Morrow, D. G. (2012). The effect of expertise on collaborative problem solving. Thinking \& Reasoning, 18(1), 32-58. https://doi.org/10.1080/13546783.2011.642206

OECD (Organisation for Economic Co-operation and Development). (2017). PISA 2015 Collaborative Problem-Solving Framework.

https://www.oecd.org/pisa/pisaproducts/Draft\%20PISA\%202015\%20Collaborative\%20Problem\%20Solving\%20Framework $\% 20$. pdf.

OERservices. (n.d.). The Five Stages of Team Development. https://courses.lumenlearning.com/sunyprinciplesmanagement/chapter/reading-the-five-stages-of-team-development/

Pei-Ling Tan, J., \& Koh, E. (2017). Situating learning analytics pedagogically: Towards an ecological lens. Learning: Research and Practice, 3(1), 1-11. https://doi.org/10.1080/23735082.2017.1305661 
Prieto, L. P., Sharma, K., Dillenbourg, P., \& Jesús, M. (2016). Teaching analytics: Towards automatic extraction of orchestration graphs using wearable sensors. Proceedings of the Sixth International Conference on Learning Analytics and Knowledge (LAK '16), 25-29 April 2016, Edinburgh, UK (pp. 148-157). New York: ACM. https://doi.org/10.1145/2883851.2883927

Reilly, J. M., \& Schneider, B. (2019). Predicting the quality of collaborative problem solving through linguistic analysis of discourse. Proceedings of the 12th International Conference on Educational Data Mining (EDM '19), 2-5 July 2019, Montreal, QC, Canada (pp. 149-157).

Reimann, P. (2009). Time is precious: Variable- and event-centred approaches to process analysis in CSCL research. International Journal of Computer-Supported Collaborative Learning, 4, 239-257. https://doi.org/10.1007/s11412$\underline{009-9070-Z}$

Rienties, B., \& Toetenel, L. (2016). The impact of learning design on student behavior, satisfaction and performance: A cross-institutional comparison across 151 modules. Computers in Human Behavior, 60, 333-341. https://doi.org/10.1016/j.chb.2016.02.074

Ron, S., Berka, C., \& Sprang, M. (2009). Neurophysiologic collaboration patterns during team problem solving. Proceedings of the Human Factors and Ergonomics Society Annual Meeting, 53(12), 804-808. https://doi.org/10.1177/154193120905301209

Roschelle, J., Dimitriadis, Y., \& Hoppe, U. (2013). Classroom orchestration: Synthesis. Computers \& Education, 69, 523526. https://doi.org/10.1016/j.compedu.2013.04.010

Ruparelia, N. B. (2010). Software development lifecycle models. ACM SIGSOFT Software Engineering Notes, 35(3), 8-13. https://doi.org/10.1145/1764810.1764814

Santagata, R., Zannoni, C., \& Stigler, J. W. (2007). The role of lesson analysis in pre-service teacher education: An empirical investigation of teacher learning from a virtual video-based field experience. Journal of Mathematics Teacher Education, 10, 123-140. https://doi.org/10.1007/s10857-007-9029-9

Scheffel, M., Tsai, Y-S., Gašević, D., \& Drachsler, H. (2019). Policy matters: Expert recommendations for learning analytics policy. In M. Scheffel, J. Broisin, V. Pammer-Schindler, A. Ioannou, \& J. Schneider (Eds.), Transforming Learning with Meaningful Technologies (pp. 510-524). Cham: Springer. https://doi.org/10.1007/978-3-030-29736-7 38

Schön, D. A. (1983). The Reflective Practitioner: How Professionals Think in Action. San Francisco: Jossey-Bass.

Scoular, C., \& Care, E. (2020). Monitoring patterns of social and cognitive student behaviors in online collaborative problem solving assessments. Computers in Human Behavior, 104, 1-8. https://doi.org/10.1016/j.chb.2019.01.007

Selwyn, N. (2019). What's the problem with learning analytics? Journal of Learning Analytics, 6(3), 11-19. https://doi.org/10.18608/jla.2019.63.3

Sergis, S., \& Sampson, D. G. (2017). Teaching and learning analytics to teacher inquiry: A systematic literature review. In A. Peña-Ayala (Ed.), Learning Analytics: Fundaments, Applications, and Trends (pp. 25-63). Cham: Springer. https://doi.org/10.1007/978-3-319-52977-6 2

Shankar, S. K., Prieto, L. P., Rodríguez-Triana, M. J., \& Ruiz-Calleja, A. (2018). A review of multimodal learning analytics architectures. Proceedings of the IEEE 18th International Conference on Advanced Learning Technologies (ICALT '18), 9-13 July 2018, Mumbai, India (pp. 212-214). IEEE. https://doi.org/10.1109/ICALT.2018.00057

Siemens, G., \& Gašević, D. (2012). Guest editorial — Learning and knowledge analytics. Educational Technology \& Society, 15(3), 1-2.

Silverman, D. (2014). Interpreting Qualitative Data (5th ed.). London: Sage.

Smith, A. (30 August 2018). Franken-algorithms: The deadly consequences of unpredictable code. The Guardian. Retrieved from https://www.theguardian.com/technology/2018/aug/29/coding-algorithms-frankenalgos-program-danger

Society for Learning Analytics Research. (n.d.). What Is Learning Analytics? https://www.solaresearch.org/about/what-islearning-analytics

Stahl, G. (2011). Rediscovering CSCL. In T. Koschmann, R. Hall, \& N. Miyaki (Eds.), CSCL2: Carrying forward the Conversation (pp. 169-184). Hillsdale, NJ: Lawrence Erlbaum Associates.

Stewart, A. E. B., Amon, M. J., Duran, N. D., \& D’Mello, S. K. (2020). Beyond team makeup: Diversity in teams predicts valued outcomes in computer-mediated collaborations. Proceedings of the 2020 CHI Conference on Human Factors in Computing Systems (CHI '20), 25-30 April 2020, Honolulu, HI, USA (pp. 1-13). New York: ACM. https://doi.org/10.1145/3313831.3376279

Stewart, A. E. B., Vrzakova, H., Sun, C., Yonehiro, J., Stone, C. A., Duran, N. D., ... D’Mello, S.K. (2019). I say, you say, we say: Using spoken language to model socio-cognitive processes during computer-supported collaborative problem solving. Proceedings of the ACM on Human-Computer Interaction, 3, 1-19. https://doi.org/10.1145/3359296 
Tsoni, R., \& Verykios, V. S. (2019). Looking for the "more knowledgeable other" through learning analytics. Proceedings of the 10th International Conference in Open and Distance Learning (ICODL '19), 22-24 November 2019, Athens, Greece (pp. 239-251). https://doi.org/10.12681/icodl.2318

Tuckman, B. W., \& Jensen, M. A. C. (1977). Stages of small-group development revisited. Group \& Organizational Studies, 2(4), 419-427. https://doi.org/10.1177/105960117700200404

Urhahne, D., Schanze, S., Bell, T., Mansfield, A., \& Holmes, J. (2010). Role of the teacher in computer-supported collaborative inquiry learning. International Journal of Science Education, 32(2), 221-243. https://doi.org/10.1080/09500690802516967

Van Leeuwen, A., van Wermeskerken, M., Erkens, G., \& Rummel, N. (2017). Measuring teacher sense making strategies of learning analytics: A case study. Learning: Research and Practice, 3(1), 42-58. https://doi.org/10.1080/23735082.2017.1284252

Verbert, K., Manouselis, N., Ochoa, X., Wolpers, M., Drachsler, H., Bosnic, I., \& Duval, E. (2012). Context-aware recommender systems for learning: A survey and future challenges. IEEE Transactions on Learning Technologies, 5(4), 318-335. https://doi.org/10.1109/TLT.2012.11

Vygotsky, L. S. (1978). Mind in Society: The Development of Higher Psychological Processes. Cambridge, MA: Harvard University Press.

Webb, N. M. (2008). Teacher practices and small-group dynamics in cooperative learning classrooms. In R. M. Gillies, A. Ashman, \& J. Terwel (Eds.), The Teacher's Role in Implementing Cooperative Learning in the Classroom (pp. 201221). New York: Springer. https://doi.org/10.1007/978-0-387-70892-8 10

Webber, S. S. (2008). Development of cognitive and affective trust in teams: A longitudinal study. Small Group Research, 39(6), 746-769. http://doi.org/10.1177/1046496408323569

Wiltshire, T. J., Steffensen, S. V., \& Fiore, S. M. (2019). Multiscale movement coordination dynamics in collaboration team problem solving. Applied Ergonomics, 79, 143-151. http://doi.org/10.1016/j.apergo.2018.07.007

Winne, P. H., \& Baker, R. S. J. D. (2013). The potentials of educational data mining for researching metacognition, motivation and self-regulated learning. Journal of Educational Data Mining, 5(1), 1-8. https://doi.org/10.5281/zenodo.3554619

Wise, A. F. (2014). Designing pedagogical interventions to support student use of learning analytics. Proceedings of the Fourth International Conference on Learning Analytics and Knowledge (LAK '14), 24-28 March 2014, Indianapolis, IN, USA (pp. 203-211). New York: ACM. https://doi.org/10.1145/2567574.2567588

Wise, A. F., \& Jung, Y. (2019). Teaching with analytics: Towards a situated model of instructional decision-making. Journal of Learning Analytics, 6(2), 53-69. https://doi.org/10.18608/jla.2019.62.4

Wise, A. F., \& Shaffer, D. W. (2015). Why theory matters more than ever in the age of big data. Journal of Learning Analytics, 2(2), 5-13. http://doi.org/10.18608/jla.2015.22.2

Yow, W. Q., \& Lim, T. Z. M. (2019). Sharing the same languages helps us work better together. Palgrave Communications, 5, 1-11. https://doi.org/10.1057/s41599-019-0365-Z

Zhang, X., Meng, Y., de Pablos, P. O., \& Sun. Y. (2019). Learning analytics in collaborative learning supported by Slack: From the perspective of engagement. Computers in Human Behavior, 92, 625-633. https://doi.org/10.1016/j.chb.2017.08.012

Zimmermann, A., Lorenz, A., \& Oppermann, R. (2007). An operational definition of context. In B. Kokinov, D. C. Richardson, T. R. Roth-Berghofer, \& L. Vieu (Eds.), CONTEXT 2007: Modeling and using context (pp. 558-571). Berlin, Heidelberg: Springer. https://doi.org/10.1007/978-3-540-74255-5_42 